\title{
Meaningful Gamification and Students' Motivation: A Strategy for Scaffolding Reading Material
}

\author{
Lynette Tan Yuen Ling \\ National University of Singapore
}

\begin{abstract}
Gamification is an innovative pedagogical strategy where digital games are used in an educational setting and as an aid to learning. Recent publications on gamification in the classroom investigate the concept of meaningful gamification, where, in line with Ryan and Deci's self-determination theory, competency, autonomy, and relatedness are prioritized. The paradigm of meaningful gamification works well as a catalyst in motivating students to read background material and grasp key concepts that facilitate a flipped classroom. This study measures the impact of meaningful gaming on students' motivation in a higher education setting. The context for this study is the module Women in Film, which is part of the Ideas and Exposition Programme at the Centre for English Language Communication, National University of Singapore.
\end{abstract}

Keywords: game-based learning; learner-centered; meaningful gamification; motivation; self-determination; serious games; technology; technology enhanced learning (TEL)

Tan, Y.L.L. (2018). Meaningful gamification and students' motivation: A strategy for scaffolding reading material. Online Learning, 22(2), 141-155.

doi:10.24059/olj.v22i2.1167

\section{Meaningful Gamification and Students' Motivation: A Strategy for Scaffolding Reading Material}

At the frontier of new and intriguing pedagogical approaches is gamification, where digital games are used in an educational setting and as an aid to learning. The allure of gaming appears to have even worried academics teaching ever-popular film studies modules. Jodi Brooks (2010) in a recent article writes the following:

As the current century is increasingly identified as the century of gaming (as opposed to the twentieth century as the century of cinema) one can only assume that questions about the discipline's value and future will continue to be raised. (p. 792)

The significance of gaming is an indisputable fact of the 21st century, bolstered by statistics such as the sale of Minecraft maker Mojang to Microsoft for $\$ 2.5$ billion (Mac, Ewalt, \& JedeurPalmgren, 2015) and pronouncements of a mass exodus of the world's population from reality to 
online games and virtual environments (McGonigal, 2011). Gamification sits well with the globalized and modern English language class in higher education, where student-centric approaches cater to a more culturally heterogeneous and technologically inclined learning environment. Distinct from game-based learning, gamification adds game elements to a nongame situation, while the former uses existing games to enhance the learning process. Notable examples of game-based learning include SimCity, Minecraft, and World of Warcraft (Al-Azawi, Al-Faliti, \& Al-Blushi, 2016, pp. 134-135).

Recent publications on gamification in the classroom investigate the concept of meaningful gamification, where, in line with Ryan and Deci's self-determination theory, competency, autonomy, and relatedness are prioritized (Ryan \& Deci, 2000a, p. 68). Meaningful gamification works as a catalyst in motivating students to read background material and grasp key concepts that in turn facilitate a flipped classroom, as students come to class with a level of competency with the material that enables them to participate in discussions. The tool of gamification also allows writing skills to be reinforced after they have been introduced in the classroom, by providing an engaging platform whereby students can practice these skills in various quests that are created for this purpose.

This study aims to measure the impact of meaningful gaming on students' motivation within a Women in Film module designed for students studying English Language Communication at the National University of Singapore (NUS). Below, I outline the theoretical framework underlying meaningful gamification and then introduce the unique context of the study.

\section{Gaming, Education, and Meaningful Gamification}

Gaming and education have long been seen as separated by a huge gulf, the former associated with a misspent youth and addiction, and the latter with a respectable acquisition of knowledge and skills needed in life. Yet the idea that the twain shall meet and that game-based learning is a reality is now gaining currency. The use of gaming in an educational context was established with the Serious Games Initiative by the Woodrow Wilson Center for International Scholars in Washington, DC, in 2002 (Michael \& Chen, 2006). What differentiates "serious games" from other forms of gaming is that education is the primary goal, rather than entertainment (Yap, 2012, p. 7). Scholars now take seriously the notion that "using games as an educational tool provides opportunities for deeper learning" (Mackay, 2013), and a Pearson research report suggests that educational digital games (1) are built on sound learning principles, (2) provide more engagement for the learner, (3) provide personalized learning opportunities, (4) teach 21st-century skills, and (5) provide an environment for authentic and relevant assessment (McClarty et al., 2012).

Recent work on gamification in the classroom shifts the focus from the generic benefits of gaming to specific game design elements, such as "reward-based gamification" techniques centered on points, levels, badges, achievements, and leaderboards (Deterding, 2012). Nicholson (2013) coined the term "meaningful gamification" as the antonym of reward-based gamification, where users are able to find "meaningful connections with the underlying non-game activities," and rewards are only used when "truly necessary" (p. 671). With meaningful gamification, the emphasis is on elements of play rather than those of scoring.

The emphasis on play rather than scoring is intimately tied to motivation. In their research on self-determination theory (SDT), Richard Ryan and Edward Deci (2000a) point to "intrinsic motivation" as a desired outcome. The researchers define intrinsic motivation as "behaviours done 
in the absence of external impetus that are inherently interesting and enjoyable" (Ryan \& Deci, 2000 b, p. 55) - and its departure from extrinsic motivation is clearly spelled out. In comparison to motivation that is externally imposed, motivation that is intrinsic is "authentic," "self-anchored or endorsed," and people who have it express more "interest," "excitement," and "confidence." These last three qualities result in "enhanced performance, persistence, and creativity," "heightened vitality," "self-esteem," and "general well-being" (Ryan \& Deci, 2000a, p. 69).

Based on their numerous empirical studies, Deci and Ryan (1985) formulated the theory of intrinsic motivation known as "cognitive evaluation theory" (CET), which posits that intrinsic motivation is driven by three supportive conditions. While intrinsic motivation may be an "inherent tendency," it is easily disrupted and needs to be maintained by these three conditions working in tandem - competency, relatedness, and autonomy (Ryan \& Deci, 2000a, p. 70). Competency refers to "the experience of behavior as effectively enacted," accompanied by the feeling of being able to meet the challenges of the task. Relatedness is attained when "people ... internalize and accept as their own the values and practices of those whom they feel, or want to feel, connected, and from contexts in which they experience a sense of belonging," and autonomy is "the experience of behaviour as volitional and reflectively self-endorsed" (Niemiec \& Ryan, 2009, pp. 135 and 139).

Deci and Ryan's three conditions map well onto the cognitive, social, and emotional components of meaningful gaming (Lee \& Hammer, 2011). Competence- the feeling of effective enactment of an objective and the ability to meet its challenges - is tied to the mastery process that games guide players through as they complete increasingly difficult tasks (Koster, as cited in Lee \& Hammer, 2011, p. 3). The emotions evoked by gaming, including curiosity, frustration, joy, and pride (Lazarro, 2004; McGonigal, 2011) enhance competence by helping "players persist through negative emotional experiences and even transform them into positive ones" (Lee \& Hammer, 2011 , p. 3). In general, gamification reframes failure as an essential part of learning and creates a sense of resilience through instant feedback. The stigma of failure evaporates when effort (the process) is rewarded, rather than mastery (the end product) (Lee \& Hammer, 2011, p. 4).

Gaming may also enhance autonomy by pushing players to "try on new identities and roles, asking them to make in-game decisions from their new vantage points" (Squire 2006; Gee, as cited in Lee \& Hammer, 2011, p. 4). Players experience the freedom afforded by these new vantage points, endorsing a new self that enables them to see things from new perspectives. By enhancing competence and autonomy and reducing a sense of failure, gaming may also nurture the sense of relatedness, or the connection that the student has with the educator. An environment where one's efforts are valued develops a context where a sense of belonging can thrive. Students internalize the values and practices of the educator because they align with their own in the first instancestudents desire their efforts to be acknowledged and validated. Thus, the potential that gamification has for raising students' intrinsic motivation appears to be high. Overall, with the meaningful gamification approach, external rewards are de-emphasized, and intrinsic motivation is prioritized, with the condition of competence being most prominent. While some preliminary research has been conducted on the effect of meaningful gamification on motivation (Nicholson, 2013), the concept is a relatively new one, and further studies, such as this one, are needed to establish a more direct connection between the two. 


\section{Context: I\&E Modules at NUS and the Pedagogical Challenge}

The environment in this gamification study is the Ideas and Exposition Programme at the Centre for English Language Communication, National University of Singapore (NUS). The program is at the outset interdisciplinary (drawing students from different faculties and departments) and learner centered: Students are able to choose from a large variety of topics, often outside of their own disciplines. Though a large part of these students are Singaporean, a significant number come from regional countries, such as Malaysia, Indonesia, Thailand, China, and India. The game medium, in line with the interdisciplinary thrust of the program, extends beyond cultural boundaries.

Women in Film, the module that is the focus of this paper, is one of 19 content-specific, rhetorically intensive writing modules offered in the program. Other modules include Sport and Socialization, Bioethics, The Detective, Science Fiction and Empire, Risk and Popular Culture, and the module that I teach, Women in Film. What links the various topics is the common set of instructional strategies used by the lecturers. A key strategy is the set of 10-12 readings that accompany the teaching of the module. Engagement with the required readings on each module ensures in large part the success of the student at completion. The readings enable the students to acquire concepts, contribute during seminars, and write intelligently for their assignments. There are a triad of pedagogical challenges faced by lecturers teaching these modules: First, students are rarely motivated to read background material (they often depend on the lecturer to explain the reading to them); second, even when they are motivated to read the material, they may not be able to decode the key issues of the reading accurately (in a recent classroom activity where I tasked first-year undergraduates to summarize the main arguments of an article, about half of their focus was inaccurate); and third, this lack of comprehension impedes their ability to contribute during seminars and ultimately to write good student papers.

This pedagogical challenge has not gone unnoticed; attempts to scaffold the reading material for students have included providing a list of questions on the specific article for them to consider or a Facebook activity where some discussion of the reading is carried out, before coming to seminars to discuss the same. While these activities have been successful to a degree, the desire to improve students' comprehension of the reading prior to their coming to class and a Centre for the Development of Teaching and Learning (CDTL) workshop at NUS led me to formulate the research hypothesis that meaningful gamification will positively impact students' motivation for prereading.

Research on prereading as an essential strategy to student performance has been tested within the domain of English language teaching (Tudor, 1989), and the relationship between prior knowledge and learning in general has already been established in pedagogical discourse. Recently, however, a body of research is once again pointing to the importance of prior knowledge for learning, alongside a key best/essential practice: "retrieval" or "testing" (see Roediger \& Butler, 2011; Van Blankenstein et al., 2013). It is this section of the module-prereading, or the engagement with reading material prior to classroom discussion-that is gamified. After discussions with Playware Studios, a new digital game was created with a story arc that featured the journey of a protagonist accompanied by a series of quests and challenges stemming from one of the main readings of the module. The challenges directed students to areas of focus and provided scaffolding for their comprehension of the material, and it also allowed for a flipped classroom where they are empowered to contribute to discussions during the seminar. This may, accordingly, foster a growing sense of competency — students are aided in their understanding of core areas in 
the readings, take part in conversations and debates about these ideas, and thus will be able to apply rhetorical and writing skills to this content in a more sophisticated manner. The combination of an enhanced competency as well as the engaging platform of gamification will, it is predicted, raise levels of students' intrinsic motivation with regard to the reading and scaffolding activities between classes. In addition to Nicholson's parameters for meaningful gamification, the three criteria utilized by Domínguez et al. (2013) and first proposed by Lee and Hammer (2011) for successful gaming in education, those of the cognitive, emotional, and social arenas, were also employed. These conditions (competency, autonomy, and relatedness) and components (cognitive, social, and emotional) were effectively worked into the game design of The Protégé, the game that Playware Studios designed specifically for Women in Film.

The narrative of The Protégé was developed to meet the requirements of scalabilityhaving a game that could ostensibly be used in all the I\&E modules. In the story, the protagonist (who has since graduated from university) receives information about his professor. The professor is missing, and the protagonist's help is needed to find him - an added cause for urgency is that the professor requires daily medication and will possibly die if he is not found in time. The student navigates through four rooms of a medical facility where he faces four quests. Each quest involves locating items that the professor has left, spawning letters that will lead to the three questions that the protagonist must answer correctly before proceeding to the next part of the story and stage of the game. Figure 1 and 2 illustrate the game environment:

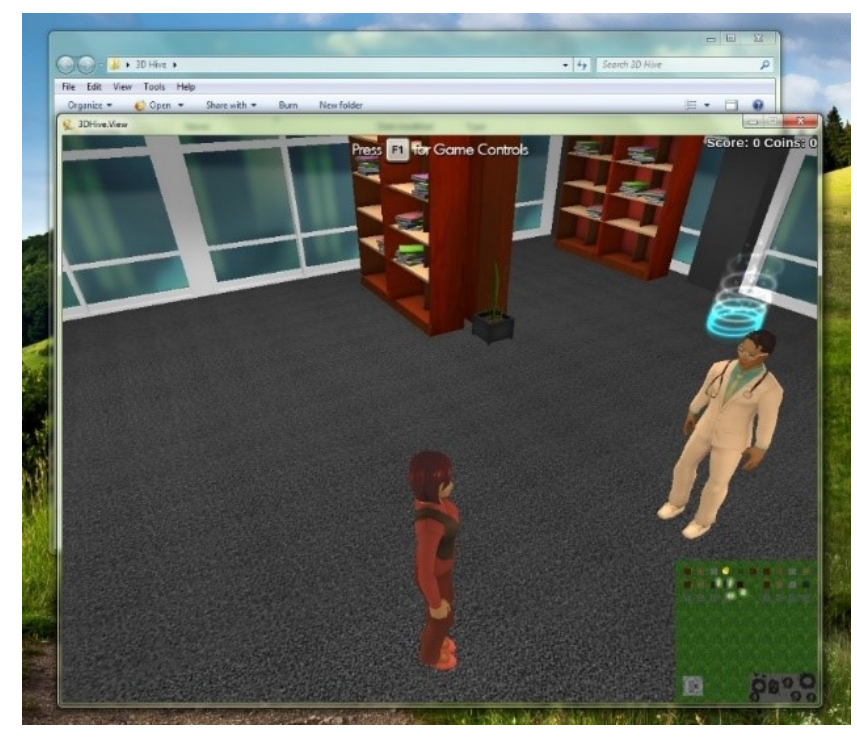

Figure 1. The three-dimensional world of The Protégé. 


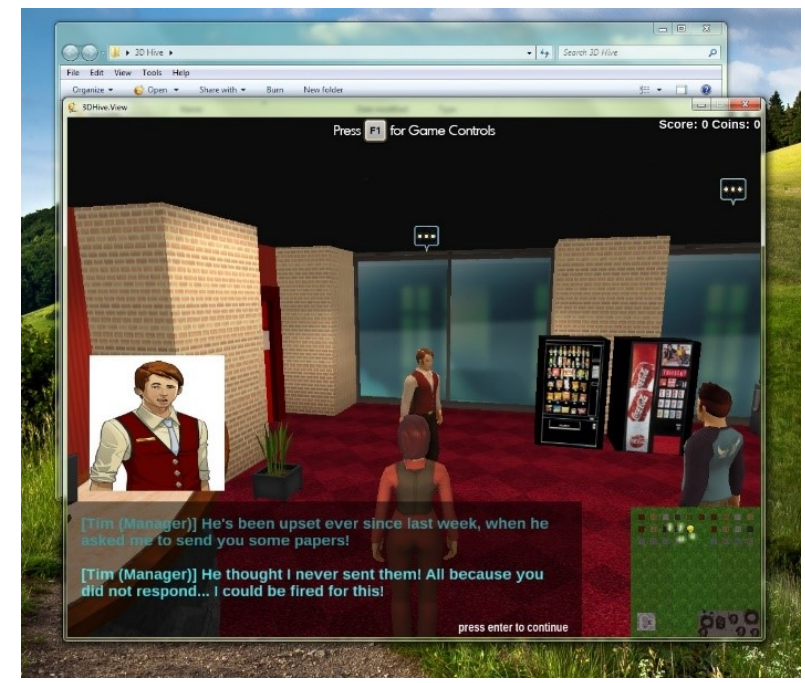

Figure 2. The narrative trajectory of The Protégé.

Integral to the game mechanics is the affordance of high-quality instant feedback. When a question is incorrectly answered, a thorough explanation for why the answer is incorrect is given immediately, and the student is given the opportunity of redoing the same question and selecting a more appropriate or correct answer. Feedback was designed to provide "corrective advice" rather than "merely pointing out strengths and weaknesses" (Nicol \& MacFarlane-Dick, 2006, p. 210), which is thought to help students self-correct and improve their self-regulated learning skills. ${ }^{1}$ Figures 3, 4, and 5 show how the quiz is presented to the student and examples of feedback after an incorrect versus correct answer.

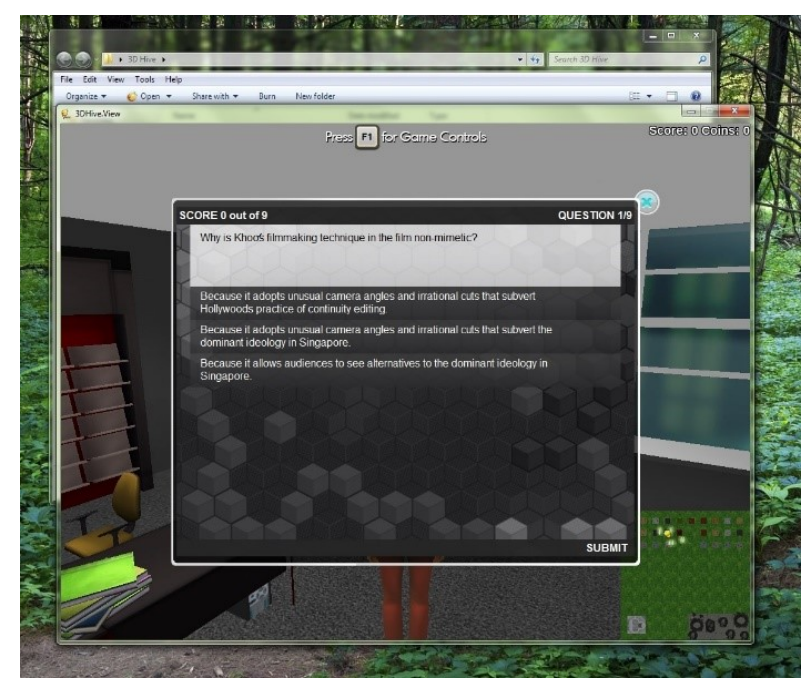

Figure 3. The quiz question and possible answers.

${ }^{1}$ A working definition of SRL: "Self-regulated learning is an active constructive process whereby learners set goals for their learning and monitor, regulate, and control their cognition, motivation, and behavior, guided and constrained by their goals and the contextual features of the environment" (Pintrich \& Zusho, 2002, p. 64). 


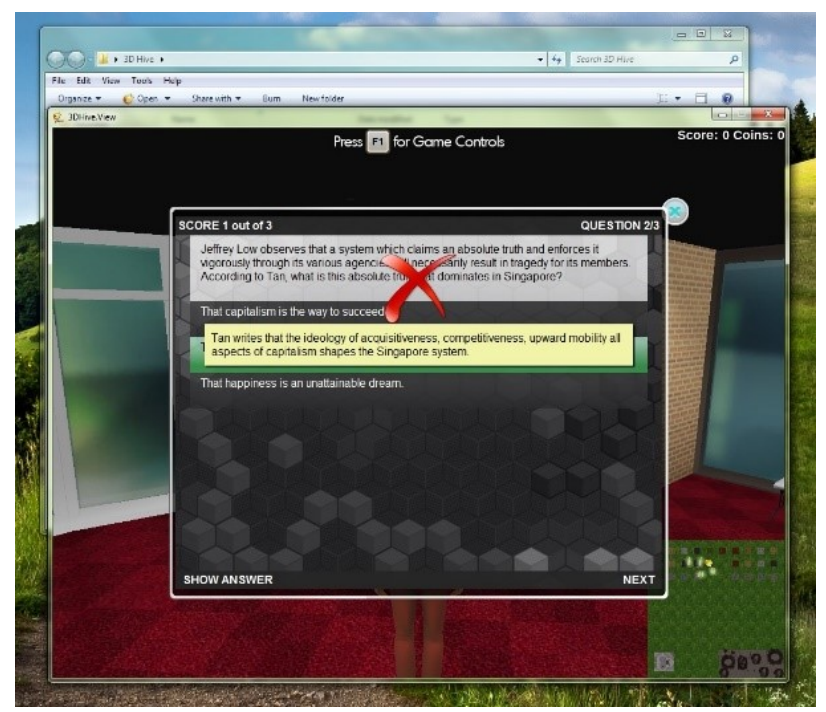

Figure 4. Incorrect answer with instant feedback.

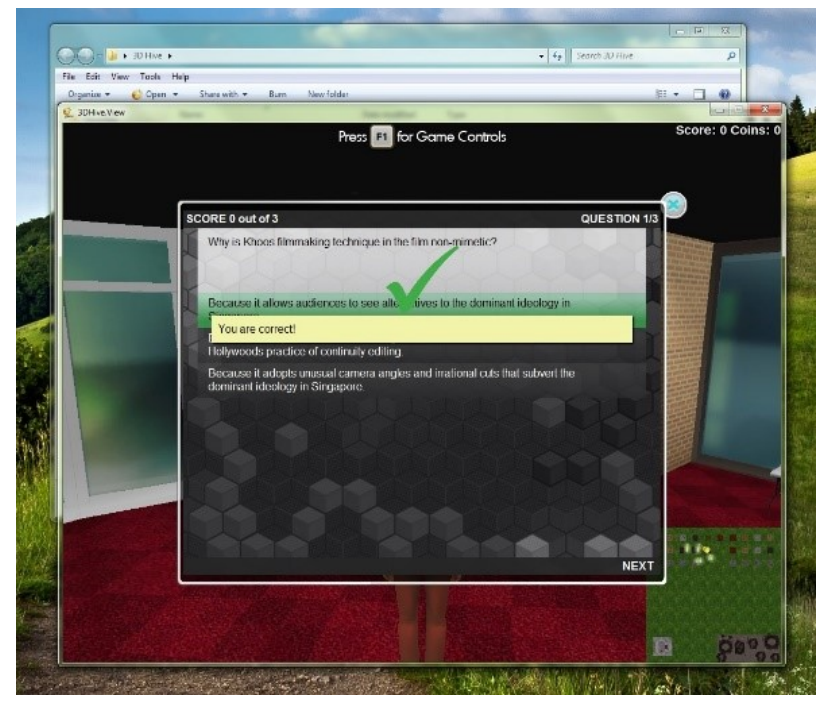

Figure 5. Correct answer with instant feedback.

The game was designed to fulfill the conditions and components that help cultivate intrinsic motivation. The conditions of competence and the provision of cognitive and emotional stimuli are facilitated when students gain mastery of the reading as they progress through the game. They will be able to meet the challenge because every wrong move is accounted for, and the right answer will become apparent. High-quality instant feedback helps reframe a wrong answer (usually associated with failure) as the route to success, and the students' effort to correct that mistake is rewarded via progression in the game. Autonomy and social stimuli occur in the game with the creation of "Rachel," the avatar protagonist, the "new self" that enables different vantage points and perspectives. In addition, the student relates to the game because mastery in the game parallels mastery of the reading material. In order to progress and succeed in the game, the student must in effect understand the key concepts of the reading material. 


\section{Methods}

The participants of this project were undergraduates at the NUS, in their first year of study. Participation was voluntary. Most of the students were Singaporean, with a number coming from regional countries, such as Malaysia, Indonesia, Thailand, China, and India. The ratio of male to female students was about 3:1. All of the students were enrolled in the module that I taught, IEM1201S Women in Film, now with the new prefix of UTW1001S. The students ranged from 19 to 25 years in age and had native to near-native abilities with the English language.

The first phase or pilot of The Protégé was initiated during e-learning week, where students are encouraged to participate in online activities in place of face-to-face sessions with the lecturer. Twenty-two students from IEM1201S watched Eric Khoo's 12 Storeys (1997) and read a corresponding section (pp. 198-206) of Kenneth Paul Tan's book on Singapore cinema on the film and then downloaded and played the game. A pretest attached to the game assessed students' comprehension of the reading material, using the same questions that would be repeated in the game, however without the aid of feedback. The pretest showed that students were unable to accurately understand key concepts of the reading: Among those whose pretest data was captured, students scored an average of $58.9 \% .^{2}$ This relates to the second and third in the triad of pedagogical challenges discussed earlier in this paper-students lacking the ability to decode the key issues of the reading accurately. In order to complete the game, students would need to answer all questions correctly, and as the procedure entails a redoing of the questions in different order, as well as receiving feedback for incorrect answers selected, this suggests that their comprehension of the material had improved.

This study sought not only to gauge these students' competence with the reading material but also their levels of intrinsic motivation with regard to The Protégé. To assess their levels of intrinsic motivation in engaging with the readings, at the conclusion of The Protégé, students completed Ryan and Deci's Intrinsic Motivation Inventory (IMI; see www.selfdeterminationtheory.org). To measure intrinsic motivation in research participants, Ryan and Deci map competency to a Perceived Competence scale, and autonomy to a Perceived Choice scale. The element of "relatedness" is not measured. Intrinsic motivation itself is tapped through Ryan and Deci's scales of Interest/Enjoyment (which is often considered a proxy for intrinsic motivation) and Pressure/Tension (which should be minimal when motivation is intrinsic).

The questionnaire is comprised of 22 items, distributed over the four constructs of interest/enjoyment, perceived competence, perceived choice, and pressure/tension. Items 1, 5, 8, 10, 14, 17, and 20 measured interest/enjoyment (e.g., "While I was working on the task I was thinking about how much I enjoyed it"); Items 4, 7, 12, 16, and 22 perceived competence (e.g., "I think I did pretty well at this activity, compared to other students"); Items 3, 11, 15, 19, and 21 perceived choice (e.g., "I felt like I was doing what I wanted to do while I was working on the task"); and Items 2, 6, 9, 13, and 18 pressure/tension (e.g., "I felt pressured while doing the task"). All items were scored on a 7-point Likert scale ranging from 1 (not at all true) to 7 (very true).

The validity of the questionnaire is based on two factors. Firstly, the IMI was used in several experiments related to intrinsic motivation and self-regulation (e.g., Ryan, 1982; Ryan, Mims, \& Koestner, 1983; Plant \& Ryan, 1985; Ryan, Connell, \& Plant, 1990; Ryan, Koestner, \&

\footnotetext{
${ }^{2}$ Due to technical problems, pretest data was not captured for $31.8 \%$ of the students.
} 
Deci, 1991; Deci, Eghrari, Patrick, \& Leone, 1994), and secondly a study by McAuley, Duncan, and Tammen (1987) examined the validity of the IMI and found strong support. The questionnaire from the IMI was modified to include a short reflection at the end so that both quantitative and qualitative results could be mined.

\section{Results: E-Learning Week and The Protégé}

After e-learning week, the quantitative and qualitative results of the intrinsic motivation questionnaire were collected and analyzed. The quantitative results of the intrinsic motivation questionnaire are tabulated in Figure 6, where the highest score is 7, and the lowest score is 1.

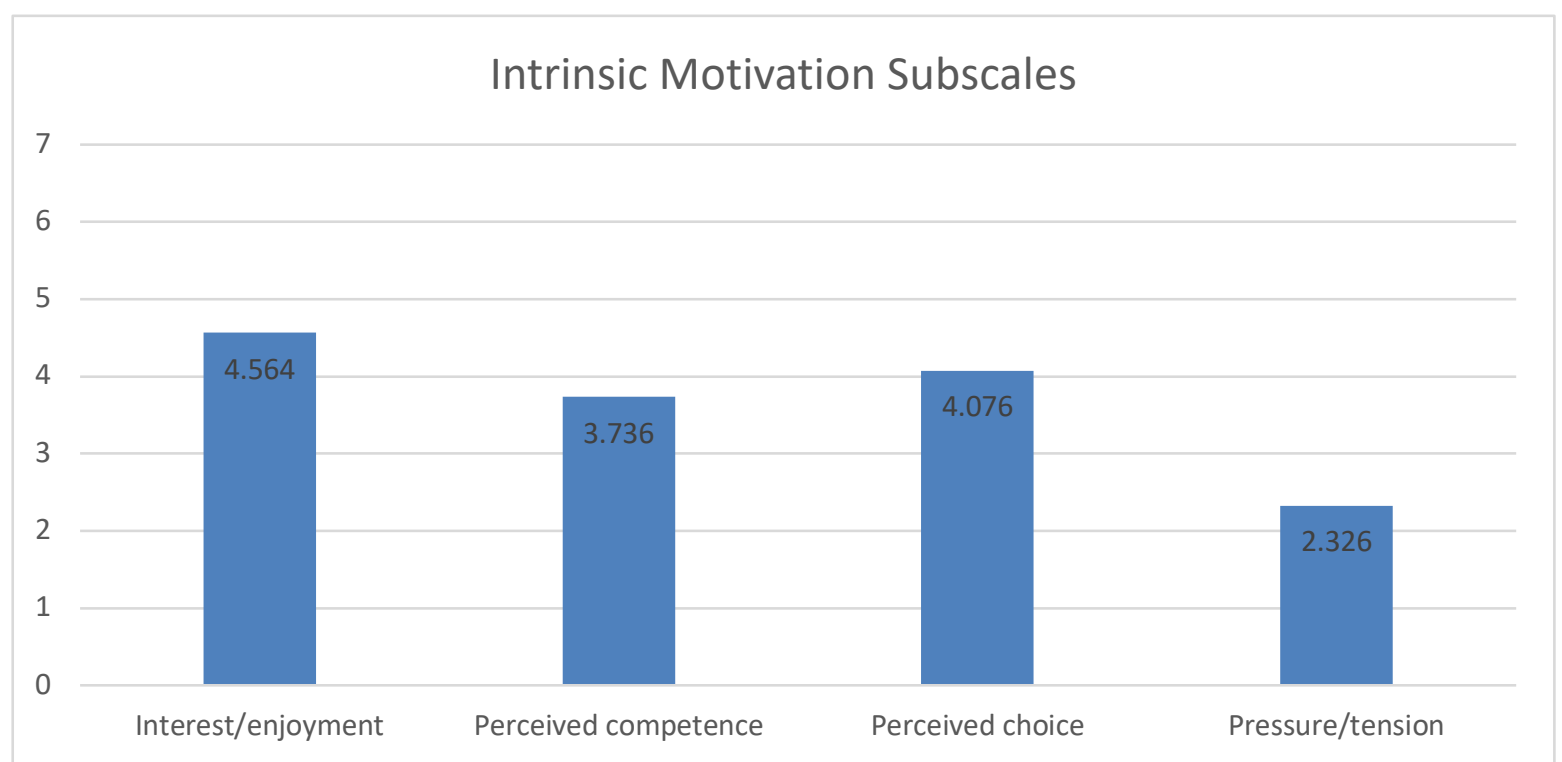

Figure 6. Initial findings: Quantitative evidence of students' intrinsic motivation.

In interpreting Figure 6, we see that the scores are consistent with students experiencing marginally higher than average levels of interest/enjoyment, as well as perceived choice (i.e., autonomy). These results are particularly significant when taking the technical issues of downloading the game into consideration (some students complained of download times of 5 hours or more) and the fact that students were told to play the game during e-learning week instead of being asked to volunteer for the task, which should have resulted in low scores for the element of perceived choice. Perceived competence received a lower score; however, on average students felt they were "somewhat competent" playing the game (this is also echoed in the qualitative results). The most dramatic indication was that of the low pressure/tension that students felt in the gamification experience, with a rating of 2.326 out of 7 .

To provide a context for the interpretation of these scores, I compared them to a study of Singaporean students performing academic project work (Liu et al., 2006). ${ }^{3}$ The study measured Ryan and Deci's constructs of interest/enjoyment, perceived competence, and perceived choice

\footnotetext{
${ }^{3}$ Liu et al. renamed the construct of "interest/enjoyment" as "intrinsic motivation" and explained that they saw the former as the biggest factor in the development of the latter. For consistency, I have retained the original title of the construct here, as well as omitted the element of relatedness, which is not measured in my study.
} 
using the same Likert-scale items used here; collected data across 254 students enrolled at seven educational institutions in Singapore; and reported results separately for two groups. For interest/enjoyment, their two groups had means of 3.94 and 3.84; for competence, means of 3.68 and 3.55; and for choice, means of 4.25 and 4.06. When pitted against the mean results in this study, with interest/enjoyment scoring 4.564, competence at 3.736, and choice at 4.076, the total mean of the three scores in the gamification study exceeded the scores of both groups in the comparison study — surpassing the first group by 0.506 and the second by 0.926 .

\section{Qualitative Results: Student Reflections}

The student reflections mostly indicated that they found the game "engaging" and "fun" and "more interesting" than working on a traditional quiz. Many also found that their understanding of the reading improved after playing the game, particularly in clearing up misconceptions that they had. Each of the statements that follow are from different students:

Student A: "Overall, playing this game was definitely more interesting than merely doing a quiz."

Student B: "This way of playing and learning at the same time is very novel and enjoyable to me compared to just reading the article and trying to understand it. The game provides a very interactive and engaging choice for me to understand and learn from the article and the movie."

Student C: "I feel that the game was an interesting way to reflect on the reading and to test my understanding of the reading. The game setting provided a stress free way of learning as it brings focus on the reading in an indirect way."

Student D: "I found the game very helpful in understanding the reading as it allowed me to identify concepts that I did not grasp very well."

Student E: "The questions in the game definitely helped me to understand the reading better and also helped me clear up some of the misconceptions that I had."

Student F: "The questions definitely motivated me to explore key ideas in our reading that relate film analysis (especially mise-en-scene), insights into ramifications of dominant ideologies in patriarchal societies, as well as the investigative role of the film-maker. The game is an interactive way in achieving the above mentioned as it creates a feeling of suspense (when I ask myself, what's next?) that is gradually uncovered along the way."

This was tied to the ability to attempt the quiz multiple times until they got the answers correct, as well as the facility of instant feedback:

Student G: "The in-game quizzes are helpful for understanding the reading and the ability to retry the quiz until all the questions are right is good as well."

However, there were two main drawbacks: download time (a few hours in some cases) and narrative dissonance or the "disconnect" between the task and the story of the game. Students consistently had technical difficulties, sometimes finding them insurmountable:

Student H: "I got booted out about halfway through the game and some of the controls didn't work for me. ... The downloading process was very difficult and long and I encountered numerous problems. I guess the technical issues could be better 
improved to make the game more enjoyable. It was a really commendable effort though, if not for the technical issues, the dialog and tasks would have been better executed."

Student I: "It does spend a lot of time downloading and updating."

Student J: "I had trouble starting the game due to technical difficulties."

It is illuminating, though, that students appreciated the facility of multiple tries as well as instant feedback, in spite of the frustration they experienced with the technical difficulty of downloading the game:

Student K: "I had quite a bit of difficulty getting the game up and running due to the download time. However once I started playing and got the hang of the game, I realised that it was actually rather addictive and I found myself repeating some of the quizzes to get the full score, it was effective in getting me to understand the reading better as it got me thinking and immediately corrected me if I got something wrong in a fun and interactive way. The addition of a storyline and a goal made the experience even more engaging."

Narrative dissonance was the other challenge faced by students, and these outweighed the comments from students who enjoyed the story:

Student L: "I did not see how the quiz needed to be placed in the context of a game or how they relate."

Student M: "At times it felt like the 'story' of the game didn't really matter - I had to just go through the doors and speak to the avatars."

Student N: "I do feel that the components of the game, namely the plot, characters and setting, are very randomly put together, in how they do not seem to make much sense."

Some students also found the availability of just one avatar too limiting, and the single-player mode isolating:

Student O: "As I was the only player I did not get to hear or understand other students' points of views and perspectives. If there could be more avatars involved, or a multiplayer aspect integrated into the game it would be perfect."

Student P: "I would definitely recommend more things like this (game) but maybe on a more social level such as having more players at once."

\section{Discussion}

In Ryan and Deci's (2000a) "Self-Determination Continuum," intrinsic motivation occurs when the "perceived locus of causality" is internal, and the "relevant regulatory processes" include "interest," "enjoyment," and "inherent satisfaction" (p. 72). As mentioned, students were not asked to volunteer for the game, and this externalized their locus of causality. However, the regulatory processes, as seen from the quantitative and qualitative results, are remarkably close to those of intrinsic motivation. Students expressed some "interest, excitement, and confidence" (Ryan \& Deci, 2000a, p. 69) in their gamification experience, with most indicating an increase in 
competence (cognitive stimuli/mastery) after playing the game. The improvement in competence takes into account not only students' qualitative comments but also the fact that in completing the game they would need to respond correctly to all questions regarding the reading material. The sense of inherent satisfaction is highlighted with the repetition of how helpful students found the game, as found in their reflections. None of the students (apart from the one that failed to download the game) experienced a sense of failure. The two challenges faced-technical issues and narrative dissonance- (mostly expressed through the qualitative evidence) did not overwhelm the students' engagement with the game to the degree that they did not benefit from the learning experience, and these two challenges will be addressed in the second run of the game, where the technical issues will be ironed out, the narrative will be adjusted, and the multiplayer facility will be provided.

The results point to the potential that meaningful gamification has in motivating and helping students in scaffolding reading material before their classes, and shows it to be not only a viable but also a worthwhile facility to invest in and develop-particularly for facilitating a flipped-classroom environment. To reiterate, the study also indicates that students' comprehension of the material improved, as the completion of the game provided evidence that inaccuracies in understanding key concepts of the reading (as manifest in the pretest) were addressed. Further studies are needed to meet the final pedagogical challenge raised in this paper: students' contribution in seminars as well as their ability to write good student papers. However, the game's potential to intrinsically motivate students as well as in aid their understanding of the associated reading material does suggest this to be a logical consequence. At present, a study is also being undertaken that compares students' preferences for various scaffolding strategies. Among these strategies is a comparison of the gamified quiz and the traditional quiz.

As a response to the rapid rate of technological advancement in society and a greater attention to not only what students are learning but how and when they learn, this paper extends research that places the student at the center of the learning process - in particular, research on students' motivation in a writing module. One of the key outcomes of this pilot project provides evidence for the use of gaming, specifically meaningful gamification, as a pedagogical tool that has a positive impact on students' motivation, by targeting a group of students pursuing the module Women in Film in a global, research-intensive university in Asia.

\section{Acknowledgements}

I would like to thank Siddharth Jain of Playware Studios for creating The Protégé for my module, as well as Alan Soong, John Yap, and Jeanette Fung for their enthusiasm, support, and advice. I would also like to acknowledge the contributions of my students who diligently completed the questionnaires for this project. 


\section{References}

Al-Azawi, R., Al-Faliti, F., \& Al-Blushi, M. (2016). Educational gamification vs. game based learning: Comparative study. International Journal of Innovation, Management and Technology, 7(4), 131. doi:10.18178/ijimt.2016.7.4.659

Brooks, J. (2010). The state of the discipline: Film studies as bad object. Continuum, 24(5), 791797.

Deci, E. L., Eghrari, H., Patrick, B. C., \& Leone, D. (1994). Facilitating internalization: The selfdetermination theory perspective. Journal of Personality, 62, 119-142.

Deterding, S. (2012). The gameful classroom. A workshop at Games. Learning \& Society, 8.0. Madison, WI.

Domínguez, A., Saenz-de-Navarrete, J., de-Marcos, L., Fernández-Sanz, L, Pagés, C., \& Martínez-Herráiz, José-Javier. (2013). Gamifying learning experiences: Practical implications and outcomes. Computers \& Education, 63, 380-392.

Lazarro, N. (2004). Why we play games: Four keys to more emotion in player experiences [PDF file]. Oakland, CA: XEODesign, Inc. Retrieved from http://twvideo01.ubmus.net/o1/vault/gdc04/slides/why we play games.pdf

Lee, J. J., \& Hammer, J. (2011). Gamification in education: What, how, why bother? Academic Exchange Quarterly, 15(2), 1-5.

Liu, W., Wong, A. F., Divaharan, S., Peer, J., Quek, C., \& Williams, M. D. (2006). Students' intrinsic motivation in project-based learning using an asynchronous discussion platform. Educational Research Journal, 21(2), 217-234. Retrieved from http://hkier.fed.cuhk.edu.hk/journal/

Mac, R., Ewalt, D. M., \& Jedeur-Palmgren, M. (2015). Inside the post-Minecraft life of billionaire gamer god Markus Persson. Forbes.

Mackay, R. F. (2013). Playing to learn: Panelists at Stanford discussion say using games as an educational tool provides opportunities for deeper learning. Retrieved from https://news.stanford.edu/2013/03/01/games-education-tool-030113/

McAuley, E., Duncan, T., \& Tammen, V. V. (1987). Psychometric properties of the Intrinsic Motivation Inventory in a competitive sport setting: A confirmatory factor analysis. Research Quarterly for Exercise and Sport, 60, 48-58.

McClarty, K. L., Orr, A., Frey, P. M., Dolan, R. P., Vassileva, V., \& McVay, A. (2012). A literature review of gaming in education [Research report]. Retrieved from https://images.pearsonassessments.com/images/tmrs/Lit_Review_of_Gaming_in_Educati on.pdf

McGonigal, J. (2011). Reality is broken: Why games make us better and how they can change the world. New York: Penguin Press.

Michael, D. R., \& Chen, S. (2006). Serious games: games that educate, train and inform. Thomson Course Technology. 
Nicholson, S. (2012). A user-centred theoretical framework for meaningful gamification. Paper presented at Games+Learning+Society 8.0, Madison, WI.

Nicholson, S. (2013). Exploring gamification techniques for classroom management. Paper presented at Games+Learning+Society 9.0, Madison, WI.

Nicholson, S. (2013). Two paths to motivation through game design elements: Reward-based gamification and meaningful gamification. iConference 2013 Proceedings (pp. 671-672). doi:10.9776/13313

Nicol, D. J., \& Macfarlane-Dick, D. (2006). Formative assessment and self-regulated learning: A model and seven principles of good feedback practice. Studies in Higher Education, 31(2), 199-218.

Niemiec, C. P., \& Ryan, R. M. (2009). Autonomy, competence, and relatedness in the classroom: Applying self-determination theory to educational practice. Theory and Research in Education, 7(2), 133-144. Sage Publications.

Pintrich, P. R., \& Zusho, A. (2002) Student motivation and self-regulated learning in the college classroom. In J. C. Smart \& W.G. Tierney (Eds.) Higher education: Handbook of theory and research (Vol. 17). New York: Agathon Press.

Plant, R. W., \& Ryan, R. M. (1985). Intrinsic motivation and the effects of self-consciousness, self-awareness, and ego-involvement: An investigation of internally-controlling styles. Journal of Personality, 53, 435-449.

Roediger, H. L., \& Butler, A. C. (2011). The critical role of retrieval practice in long-term retention. Trends in Cognitive Sciences, 15(1), 20-27. doi:10.1016/j.tics.2010.09.003

Ryan, R. M. (1982). Control and information in the intrapersonal sphere: An extension of cognitive evaluation theory. Journal of Personality and Social Psychology, 43, 450-461.

Ryan, R. M., Connell, J. P., \& Plant, R. W. (1990). Emotions in non-directed text learning. Learning and Individual Differences, 2, 1-17.

Ryan, R. M., \& Deci, E. L. (2000a). Self-determination theory and the facilitation of intrinsic motivation, social development, and well-being. American Psychologist, 55(1), 68-78.

Ryan, R. M., \& Deci, E. L. (2000b). Intrinsic and extrinsic motivations: Classic definitions and new directions. Contemporary Educational Psychology, 25, 54-67.

Ryan, R. M., Koestner, R., \& Deci, E. L. (1991). Varied forms of persistence: When free-choice behavior is not intrinsically motivated. Motivation and Emotion, 15, 185-205.

Ryan, R. M., Mims, V., \& Koestner, R. (1983). Relation of reward contingency and interpersonal context to intrinsic motivation: A review and test using cognitive evaluation theory. Journal of Personality and Social Psychology, 45, 736-750.

Squire, K. (2006). From content to context: Videogames as designed experience. Educational Researcher, 35(8), 19-29. doi:10.3102/0013189X035008019

Tudor, I. (1989). Pre-reading: A categorization of formats. System, 17(3), 323-338. doi:10.1016/0346-251X(89)90005-5 
Van Blankenstein, F. M., Dolmans, D. H. J. M., Van der Vleuten, C. P. M, \& Schmidt, H. G. (2013). Relevant prior knowledge moderates the effect of elaboration during small group discussion on academic achievement. Instructional Science, 41(4), 729-744. doi:10.1007/s1 1251-012-9252-3

Yap, J. Y. G. (2012). Immersive simulation games: A case study of learning in a 3-dimensional multi-user virtual environment (Unpublished master's thesis).

Zyda, M. (2005). From visual stimulation to virtual reality to games. Computer, 38(9), 25-32. 
Meaningful Gamification and Students' Motivation: A Strategy for Scaffolding Reading Material 